\title{
The Finite Difference Method Of Discontinuous Constraint Slabs
}

\author{
J.C. WANG ${ }^{1, a}$, J.H.ZHOU ${ }^{1}$, M.X.PAN ${ }^{1}$, D.Y.ZHANG ${ }^{1}$ \\ ${ }^{1}$ Shenyang Jianzhu University, 110168, Shenyang, Liaoning, China
}

\begin{abstract}
With the improvement of building standard, structural form becomes more and more complicated. The utility rate of special-shaped column, corner window and cantilever structure is higher and higher, which often makes reinforced concrete floor slabs in a discontinuous constraint state. To make the design of discontinuous constraint slabs more scientific, the author puts forward a kind of numerical method that can solve the problem of low calculation precision .On this basis, the numerical method is applied to solve the problem of rectangular slabs with two simply supported and the other with part of simply supported and part of clamped having a theoretical analysis of the result to verify that the calculation method is correct. The result shows :1. For discontinuous constraint slabs, the displacement difference is large and the average is $10 \% \sim 20 \%$ when it comes to whether the method is adopted or not. 2. For discontinuous constraint slabs, higher precision is obtained by using the numerical method proposed in this paper. And it is necessary to consider the influence of boundary constraints when we design discontinuous Constraint slabs.
\end{abstract}

Keyword: Concrete slabs, Discontinuous constraint, Numerical method.

\section{INTRODUCTION}

The boundary conditions of floor can be divided into two categories. One is comprehensive boundary condition, the other is mixed boundary condition (referring to the edge of the rectangular slab with two or over two kinds of boundary conditions). In general, slabs with comprehesive boundary conditions are known as simple constraint slabs; Slabs with mixed boundary conditions are known as complex constraint slabs. Indeed,researches on simple constraint slabs are fruitful, whereas the complex constraint slabs are studied on starting late in engineering community ${ }^{[1 \sim 4]}$.Eyre was the first to introduce a question with regard to free vibration problem of rectangular slabs with three simply supported boundaries and the other part of simply supported boundaries and part of builtin boundaries, and gave the relevant solutions.On this basis, WangGang, Qingxiang Wang and others also studied successively on the vibration and carrying capacity of discontinuous constraint slabs, but obtained few breakthrough results ${ }^{[\sim 7]}$. On the basis of the elastic slab theory, I will present numerical method for the complex constrained slabs to you combined with the finite difference method. Strict as it is,the method considers complex constraint situation,thus giving you more accurate calculation results than simplified processing method and providing technical support for the design of slabs.

\section{BASIC EQUATION OF BENDING ABOUT THE COMPLICATED CONSTRAINT SLAB}

For complex constraint elastic thin slabs made up of homogeneous isotropic materials, taking Kirchhoff assumption, the deflection of slabs $\omega(x, y)$ and the uniformly distributed load $q_{0}$ shall meet the following differential equation ${ }^{[1]}$ :

$$
\frac{\partial^{4} \omega}{\partial x^{4}}+2 \frac{\partial^{4} \omega}{\partial x^{2} \partial y^{2}}+\frac{\partial^{4} \omega}{\partial y^{4}}=\frac{q_{0}}{D}
$$

$D=E t^{3} / 12\left(1-\mu^{2}\right)$-The flexural rigidity of the slab, $E=$ The elastic modulus of concrete; $t=$ The thickness of the slab; $\mu=$ The poisson's ratio of concrete.

The relationship between deflection and bending moment is as follows:

$$
\begin{aligned}
& M_{x}=-D\left(\frac{\partial^{2} \omega}{\partial x^{2}}+\mu \frac{\partial^{2} \omega}{\partial y^{2}}\right) \\
& M_{y}=-D\left(\frac{\partial^{2} \omega}{\partial y^{2}}+\mu \frac{\partial^{2} \omega}{\partial x^{2}}\right)
\end{aligned}
$$

Where $M x=$ the moment around $y$ axis; $M y=$ the moment around $\mathrm{x}$ axis.

\section{FORMULA OF FINITE DIFFERENCE METHOD ABOUT COMPLEX CONSTRAINT SLAB}

Formula(1) is a four order partial differential equation, it is difficult to get its analytical solution. so the displacement of the slab is obtained through finite difference method. For example the node 0 in Figure 1.

\footnotetext{
${ }^{\mathrm{a}}$ Corresponding author: wangjianchao005@163.com
} 
$\left\{\begin{array}{l}\left(\frac{\partial^{4} \omega}{\partial x^{4}}\right)_{0}=\frac{1}{h^{4}}\left[6 \omega_{0}-4\left(\omega_{1}+\omega_{3}\right)+\left(\omega_{9}+\omega_{11}\right)\right] \\ \left(\frac{\partial^{4} \omega}{\partial x^{2} \partial y^{2}}\right)_{0}=\frac{1}{h^{4}}\left[\begin{array}{l}4 \omega_{0}-2\left(\omega_{1}+\omega_{2}+\omega_{3}+\omega_{4}\right) \\ +\left(\omega_{5}+\omega_{6}+\omega_{7}+\omega_{8}\right)\end{array}\right] \\ \left(\frac{\partial^{4} \omega}{\partial y^{4}}\right)_{0}=\frac{1}{h^{4}}\left[6 \omega_{0}-4\left(\omega_{2}+\omega_{4}\right)+\left(\omega_{10}+\omega_{12}\right)\right]\end{array}\right.$

$20 \omega_{0}-8\left(\omega_{1}+\omega_{2}+\omega_{3}+\omega_{4}\right)+2\left(\omega_{5}+\omega_{6}+\omega_{7}+\omega_{8}\right)$

$+\left(\omega_{9}+\omega_{10}+\omega_{11}+\omega_{12}\right)=\frac{q_{0} h^{4}}{D}$.

$\omega_{i}=$ Nodal displacement in the slab; $h=$ The length of the grid.

By the same token, the difference formula of moment 0 is as follows:

$\left\{\begin{array}{l}\left(M_{x}\right)_{0}=\frac{D}{h^{2}}\left[2(1+\mu) \omega_{0}-\left(\omega_{1}+\omega_{3}\right)-\mu\left(\omega_{2}+\omega_{4}\right)\right] \\ \left(M_{y}\right)_{0}=\frac{D}{h^{2}}\left[2(1+\mu) \omega_{0}-\left(\omega_{2}+\omega_{4}\right)-\mu\left(\omega_{1}+\omega_{3}\right)\right]\end{array}\right.$

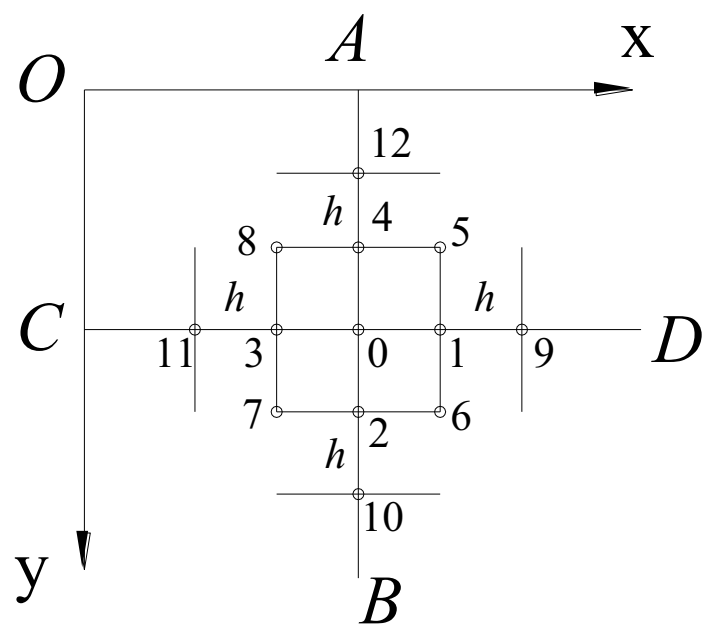

Figure 1. Schematic diagram of node.

\section{BOUNDARY CONDITION PROCESSING ABOUT COMPLEX CONSTRAINT SLAB}

For complex constraint slabs, there are at least a combination of two out of simply supported boundary, free boundary and built-in boundary in a straight edge with other straight edges simple or complex constraints. For example in Fig.2, this paper aims to present you with the thought of dealing with simple boundary and complex boundary.Assume that fig. 2 is a rectangular thin slab with boundary $\mathrm{AB}$ and $\mathrm{AD}$ clamped (simple boundary), the other for complex boundary (half clamped and half simply supported).

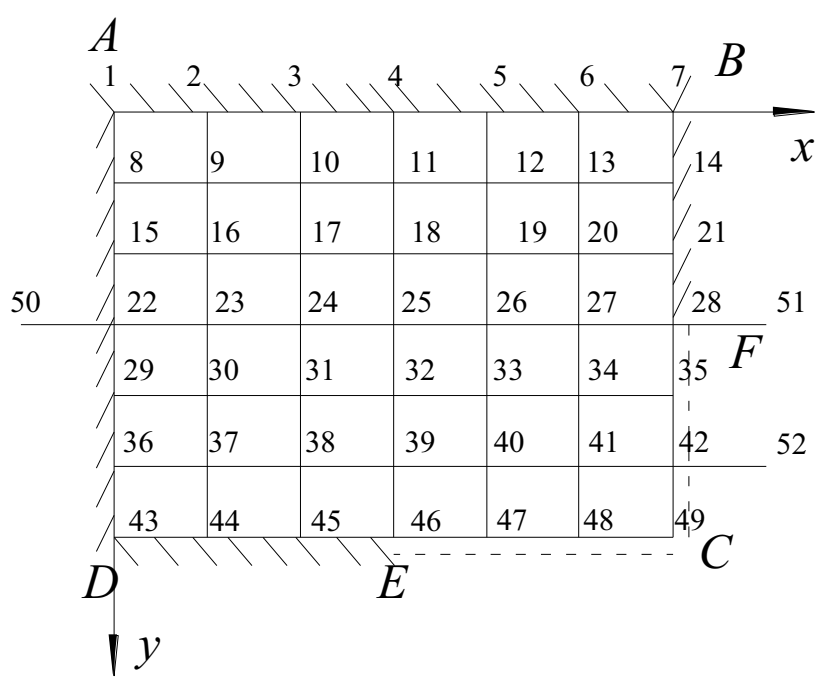

Figure 2. Boundary conditions of slabs.

Node 22: It is a built-in boundary, so the boundary displacement and first derivative of the displacement should be equal to zero,namely:

$(\omega)_{22}=0, \quad\left(\frac{\partial \omega}{\partial x}\right)_{22}=\frac{\omega_{23}-\omega_{50}}{2 h}=0$

Node 42: It is a simply supported constraint, so the boundary displacement and the second derivative of displacement should be equal to zero, namely:

$(\omega)_{42}=0, \quad\left(\frac{\partial^{2} \omega}{\partial x^{2}}\right)_{42}=\frac{\omega_{52}+\omega_{41}-2 \omega_{42}}{h^{2}}=0$

Node 28:In the intersection point with clamped and simply supported constraints, strictly speaking, the point neither belongs to clamped supported constraint nor belongs to the simply supported constraint. The point will be regarded as the combination of clamped and simply supported constraints in this article. According to the average of the two considerations, the specific calculation formula is as follows:

$(\omega)_{28}=0$,

$\frac{1}{2}\left[\left(\frac{\partial^{2} \omega}{\partial x^{2}}\right)_{28}+\left(\frac{\partial \omega}{\partial x}\right)_{28}\right]$

$=\left[(2+h) \omega_{51}-(h-2) \omega_{27}-4 \omega_{28}\right]=0$.

If there is a free boundary, $\omega(x, y)$ of every point on the side should be regard as an unknown quantity.Equations of every point on the free boundary can be obtained through formula(8).

\section{THE COMPARISON OF CALCULATION RESULTS ABOUT COMPLEX CONSTRAINT SLAB}

In a high-rise residential building with Short shear wall structure, the corner window is set in the corner. Due to the need to set outtrigger, the floor bove corner window will be a discontinuous constraint slab with a mix of clamped and simply supported. For a floor with supporting form shown in 
figure 2 , it can be solved through the above method . Suppose $\mathrm{AB}=\mathrm{AD}=3 \mathrm{~m}$, for convenience the grid length are all $\mathrm{h}=$ $0.5 \mathrm{~m}$ and the grid nodal number are shown in figure 2 .

Table 1 records $\mathrm{z}$ displacement about every point in the slab(positive direction displacement is said the same as the direction of $\left.\mathrm{q}_{0}\right) . \quad \mathrm{S}_{1}=\mathrm{q}_{0} \mathrm{~h}^{4} / \mathrm{D}, \omega=0.358 \mathrm{q}_{0} \mathrm{~h}^{4} / \mathrm{D}$. when $\mathrm{q}_{0}$ units off for $\mathrm{kN} / \mathrm{m}^{2}$, h units off for $\mathrm{m}$, D units off for kN.m.The point displacement not listed in the table is zero.

Table 1. Nodal displacement of slabs with complex support.

\begin{tabular}{cccccccccc}
\hline $\mathrm{n}$ & $\begin{array}{c}\text { Dis } \\
\left(\mathrm{S}_{1}\right)\end{array}$ & $\mathrm{n}$ & $\begin{array}{c}\text { Dis } \\
\left(\mathrm{S}_{1}\right)\end{array}$ & $\mathrm{n}$ & $\begin{array}{c}\text { Dis } \\
\left(\mathrm{S}_{1}\right)\end{array}$ & $\mathrm{n}$ & $\begin{array}{c}\text { Dis } \\
\left(\mathrm{S}_{1}\right)\end{array}$ & $\mathrm{n}$ & $\begin{array}{c}\text { Dis } \\
\left(\mathrm{S}_{1}\right)\end{array}$ \\
\hline 9 & 0.36 & 16 & 0.74 & 23 & 0.91 & 30 & 0.79 & 37 & 0.41 \\
10 & 0.74 & 17 & 1.57 & 24 & 1.97 & 31 & 1.74 & 38 & 0.92 \\
11 & 0.91 & 18 & 1.97 & 25 & 2.52 & 32 & 2.31 & 39 & 1.34 \\
12 & 0.79 & 19 & 1.74 & 26 & 2.31 & 33 & 2.20 & 40 & 1.35 \\
13 & 0.41 & 20 & 0.92 & 27 & 1.34 & 34 & 1.35 & 41 & 0.86 \\
\hline
\end{tabular}

In order to obtain the difference of the results when complex constraints are imposed on the slab or not, so the author make boundary $\mathrm{BC}$ and $\mathrm{CD}$ in figure 2 respectively with fully clamped and simply supported constraint .

Table 2. Nodal displacement of slabs with BC, CD clamped constraint

\begin{tabular}{llllllllll}
\hline $\mathrm{n}$ & $\begin{array}{l}\text { Dis } \\
\left(\mathrm{S}_{1}\right)\end{array}$ & $\mathrm{n}$ & $\begin{array}{l}\text { Dis } \\
\left(\mathrm{S}_{1}\right)\end{array}$ & $\mathrm{n}$ & $\begin{array}{l}\text { Dis } \\
\left(\mathrm{S}_{1}\right)\end{array}$ & $\mathrm{n}$ & $\begin{array}{l}\text { Dis } \\
\left(\mathrm{S}_{1}\right)\end{array}$ & $\mathrm{n}$ & $\begin{array}{l}\text { Dis } \\
\left(\mathrm{S}_{1}\right)\end{array}$ \\
\hline 9 & 0.34 & 16 & 0.68 & 23 & 0.81 & 30 & 0.68 & 37 & 0.34 \\
10 & 0.68 & 17 & 1.39 & 24 & 1.66 & 31 & 1.39 & 38 & 0.68 \\
11 & 0.81 & 18 & 1.66 & 25 & 2.00 & 32 & 1.66 & 39 & 0.81 \\
12 & 0.68 & 19 & 1.34 & 26 & 1.66 & 33 & 1.39 & 40 & 0.68 \\
13 & 0.34 & 20 & 0.68 & 27 & 0.81 & 34 & 0.68 & 41 & 0.34 \\
\hline
\end{tabular}

Table 3. Nodal displacement of slabs with BC, CD simply supported constraint.

\begin{tabular}{llllllllll}
\hline $\mathrm{n}$ & $\begin{array}{l}\text { dis } \\
\left(\mathrm{S}_{1}\right)\end{array}$ & $\mathrm{n}$ & $\begin{array}{l}\text { dis } \\
\left(\mathrm{S}_{1}\right)\end{array}$ & $\mathrm{n}$ & $\begin{array}{l}\text { dis } \\
\left(\mathrm{S}_{1}\right)\end{array}$ & $\mathrm{n}$ & $\begin{array}{l}\text { dis } \\
\left(\mathrm{S}_{1}\right)\end{array}$ & $\mathrm{n}$ & $\begin{array}{l}\text { dis } \\
\left(\mathrm{S}_{1}\right)\end{array}$ \\
\hline 9 & 0.39 & 16 & 0.83 & 23 & 1.06 & 30 & 1.01 & 37 & 0.65 \\
10 & 0.83 & 17 & 1.80 & 24 & 2.33 & 31 & 2.21 & 38 & 1.39 \\
11 & 1.06 & 18 & 2.33 & 25 & 3.03 & 32 & 2.86 & 39 & 1.78 \\
12 & 1.01 & 19 & 2.21 & 26 & 2.86 & 33 & 2.70 & 40 & 1.68 \\
13 & 0.65 & 20 & 1.39 & 27 & 1.78 & 34 & 1.68 & 41 & 1.05 \\
\hline
\end{tabular}

From table 1 to 3 , you can see that the difference of displacement is large with the maximum near the midspan when applying to different constraint conditions .

Similarly, the moment corresponding to the above three kinds of boundary conditions are shown in table 4 to 6 . the value for the moment in the table is about $\mathrm{u}=0.2 . \mathrm{S}_{2}=\mathrm{q}_{0} \mathrm{~h}^{3}$.

Table 4. Node bending moment of slabs with complex support.

\begin{tabular}{lllllllll}
$\mathrm{n}$ & $\begin{array}{l}\mathrm{M}_{\mathrm{x}} \\
\left(\mathrm{S}_{2}\right)\end{array}$ & $\begin{array}{l}\mathrm{M}_{\mathrm{y}} \\
\left(\mathrm{S}_{2}\right)\end{array}$ & $\mathrm{n}$ & $\begin{array}{l}\mathrm{M}_{\mathrm{x}} \\
\left(\mathrm{S}_{2}\right)\end{array}$ & $\begin{array}{l}\mathrm{M}_{\mathrm{y}} \\
\left(\mathrm{S}_{2}\right)\end{array}$ & $\mathrm{n}$ & $\begin{array}{l}\mathrm{M}_{\mathrm{x}} \\
\left(\mathrm{S}_{2}\right)\end{array}$ & $\begin{array}{l}\mathrm{M}_{\mathrm{y}} \\
\left(\mathrm{S}_{2}\right)\end{array}$ \\
\hline 2 & -0.72 & -0.14 & 17 & 0.52 & 0.52 & 31 & 0.67 & 0.5 \\
3 & -1.48 & -0.30 & 18 & 0.63 & 0.72 & 32 & 0.89 & 0.83 \\
4 & -1.82 & -0.36 & 19 & 0.50 & 0.67 & 33 & 0.88 & 0.88 \\
5 & -1.58 & -0.32 & 20 & 0.12 & 0.13 & 34 & 0.60 & 0.60 \\
6 & -0.82 & -0.16 & 21 & -0.37 & -1.85 & 36 & -0.16 & -0.82 \\
8 & -0.14 & -0.72 & 22 & -0.36 & -1.82 & 37 & 0.01 & -0.10 \\
9 & -0.03 & -0.03 & 23 & 0.26 & -0.09 & 38 & 0.13 & 0.12 \\
10 & -0.05 & 0.20 & 24 & 0.72 & 0.63 & 39 & 0.45 & 0.48 \\
11 & -0.09 & 0.26 & 25 & 0.92 & 0.92 & 40 & 0.60 & 0.60 \\
12 & -0.10 & 0.24 & 26 & 0.83 & 0.89 & 41 & 0.45 & 0.45 \\
13 & -0.10 & 0.01 & 27 & 0.48 & 0.45 & 44 & -0.82 & -0.16 \\
14 & -0.16 & -0.82 & 28 & -0.11 & -0.54 & 45 & -1.85 & -0.37 \\
15 & -0.30 & -1.48 & 29 & -0.32 & -1.58 & 46 & -0.54 & -0.11 \\
16 & 0.20 & -0.05 & 30 & 0.24 & -0.10 & 47 & 0.00 & 0.00 \\
\hline
\end{tabular}

Table 5. Node bending moment of slabs with BC, CD clamped constraint.

\begin{tabular}{lllllllll}
\hline $\mathrm{n}$ & $\begin{array}{l}\mathrm{M}_{\mathrm{x}} \\
\left(\mathrm{S}_{2}\right)\end{array}$ & $\begin{array}{l}\mathrm{M}_{\mathrm{y}} \\
\left(\mathrm{S}_{2}\right)\end{array}$ & $\mathrm{n}$ & $\begin{array}{l}\mathrm{M}_{\mathrm{x}} \\
\left(\mathrm{S}_{2}\right)\end{array}$ & $\begin{array}{l}\mathrm{M}_{\mathrm{y}} \\
\left(\mathrm{S}_{2}\right)\end{array}$ & $\mathrm{n}$ & $\begin{array}{l}\mathrm{M}_{\mathrm{x}} \\
\left(\mathrm{S}_{2}\right)\end{array}$ & $\begin{array}{l}\mathrm{M}_{\mathrm{y}} \\
\left(\mathrm{S}_{2}\right)\end{array}$ \\
\hline 2 & -0.68 & -0.14 & 18 & 0.63 & 0.65 & 33 & 0.53 & 0.53 \\
3 & -1.36 & -0.27 & 19 & 0.53 & 0.53 & 34 & 0.21 & 0.01 \\
4 & -1.61 & -0.32 & 20 & 0.21 & 0.01 & 35 & -0.27 & -1.36 \\
5 & -1.36 & -0.27 & 21 & -0.27 & -1.36 & 36 & -0.14 & -0.68 \\
6 & -0.68 & -0.14 & 22 & -0.32 & -1.61 & 37 & 0.00 & 0.00 \\
8 & -0.14 & -0.68 & 23 & 0.24 & 0.00 & 38 & 0.01 & 0.21 \\
9 & 0.00 & 0.00 & 24 & 0.65 & 0.63 & 39 & 0.00 & 0.24 \\
10 & 0.01 & 0.21 & 25 & 0.79 & 0.79 & 40 & 0.01 & 0.21 \\
11 & 0.00 & 0.24 & 26 & 0.65 & 0.63 & 41 & 0.00 & 0.00 \\
12 & 0.01 & 0.21 & 27 & 0.24 & 0.00 & 42 & -0.14 & -0.68 \\
13 & 0.00 & 0.00 & 28 & -0.32 & -1.61 & 44 & -0.68 & -0.14 \\
14 & -0.14 & -0.68 & 29 & -0.27 & -1.36 & 45 & -1.36 & -0.27 \\
15 & -0.27 & -1.36 & 30 & 0.21 & 0.01 & 46 & -1.61 & -0.32 \\
16 & 0.21 & 0.01 & 31 & 0.53 & 0.53 & 47 & -1.36 & -0.27 \\
17 & 0.53 & 0.53 & 32 & 0.63 & 0.65 & 48 & -0.68 & -0.14 \\
\hline
\end{tabular}

Table 6. Nodal bending moment of slabs with $\mathrm{BC}, \mathrm{CD}$ hinge constraint.

\begin{tabular}{lllllllll}
\hline $\mathrm{n}$ & $\begin{array}{l}\mathrm{M}_{\mathrm{x}} \\
\left(\mathrm{S}_{2}\right)\end{array}$ & $\begin{array}{l}\mathrm{M}_{\mathrm{y}} \\
\left(\mathrm{S}_{2}\right)\end{array}$ & $\mathrm{n}$ & $\begin{array}{l}\mathrm{M}_{\mathrm{x}} \\
\left(\mathrm{S}_{2}\right)\end{array}$ & $\begin{array}{l}\mathrm{M}_{\mathrm{y}} \\
\left(\mathrm{S}_{2}\right)\end{array}$ & $\mathrm{n}$ & $\begin{array}{l}\mathrm{M}_{\mathrm{x}} \\
\left(\mathrm{S}_{2}\right)\end{array}$ & $\begin{array}{l}\mathrm{M}_{\mathrm{y}} \\
\left(\mathrm{S}_{2}\right)\end{array}$ \\
\hline 2 & -0.77 & -0.15 & 16 & 0.17 & -0.11 & 30 & 0.17 & -0.11 \\
3 & -1.65 & -0.33 & 17 & 0.54 & 0.54 & 31 & 0.54 & 0.54 \\
4 & -2.12 & -0.42 & 18 & 0.71 & 0.77 & 32 & 0.71 & 0.77 \\
5 & -2.02 & -0.40 & 19 & 0.69 & 0.81 & 33 & 0.69 & 0.81 \\
6 & -1.29 & -0.26 & 20 & 0.46 & 0.63 & 34 & 0.46 & 0.63 \\
8 & -0.15 & -0.77 & 22 & -0.42 & -2.12 & 36 & -0.42 & -2.12 \\
9 & -0.07 & -0.07 & 23 & 0.24 & -0.16 & 37 & 0.24 & -0.16 \\
10 & -0.11 & 0.17 & 24 & 0.77 & 0.71 & 38 & 0.77 & 0.71 \\
11 & -0.16 & 0.24 & 25 & 1.04 & 1.04 & 39 & 1.04 & 1.04 \\
12 & -0.13 & 0.27 & 26 & 1.00 & 1.07 & 40 & 1.00 & 1.07 \\
13 & -0.04 & 0.26 & 27 & 0.64 & 0.81 & 41 & 0.64 & 0.81 \\
15 & -0.33 & -1.65 & 29 & -0.40 & -2.02 & 42 & -0.40 & -2.02 \\
\hline
\end{tabular}

To obtain difference of the displacement value from every node under three constraints, we can see the figures below.Displacement diagram of node 22-28 are shown in Figure 3 and displacement diagram of node 3,10,17,24,31,38,45 are shown in Figure 4.

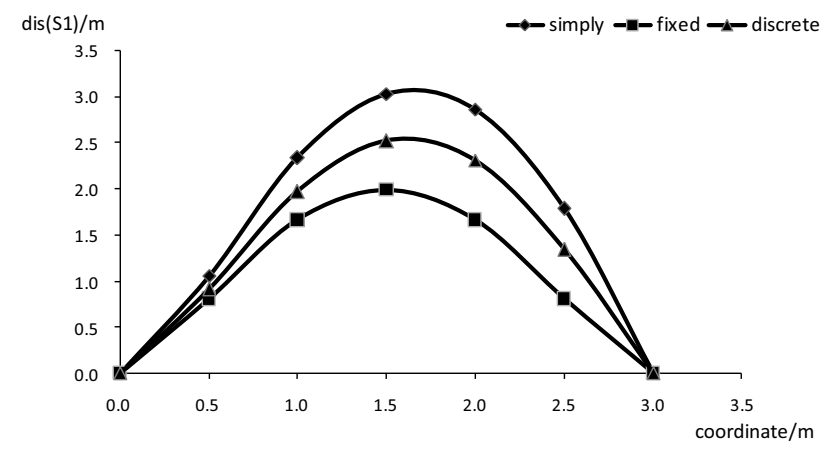

Figure 3. Displacement diagram of node 22-28. 


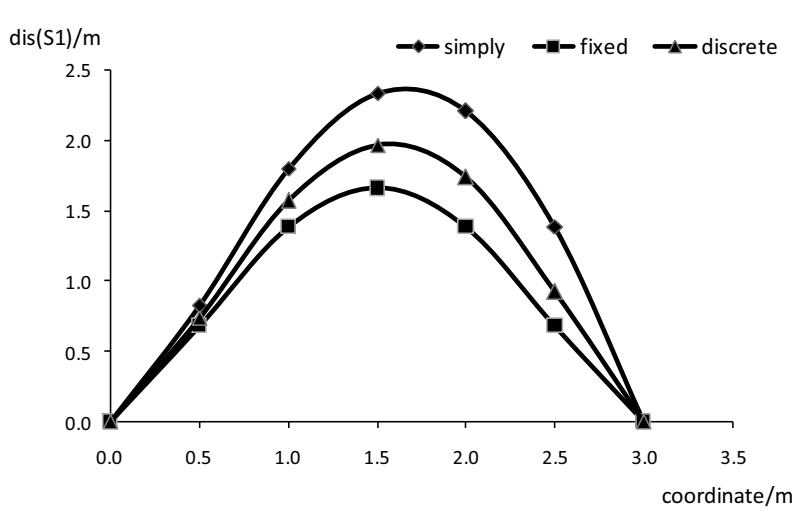

Figure 4. Displacement diagram of node 3,10,17,24,31,38,45.

As is shown in figure 5, My changes with $\mathrm{X}$ including node 22 to 28; As is shown in figure $6, \mathrm{Mx}$ changes with $\mathrm{y}$ including node $3,10,17,24,31,38$. and they are all under three constraints.

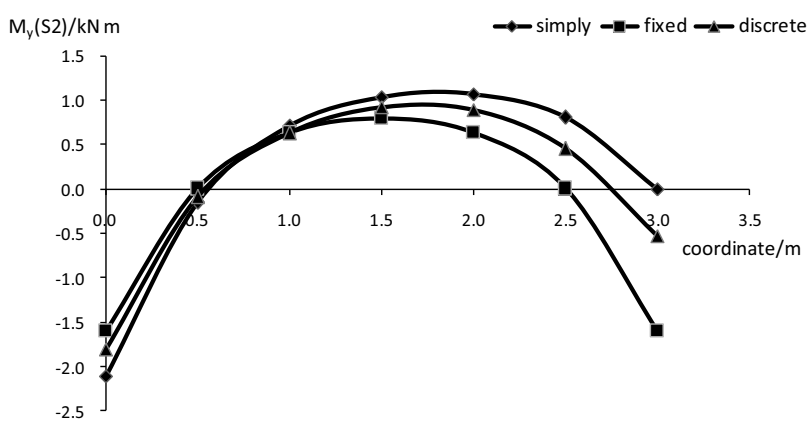

Figure 5. My diagram of node 22 28 .

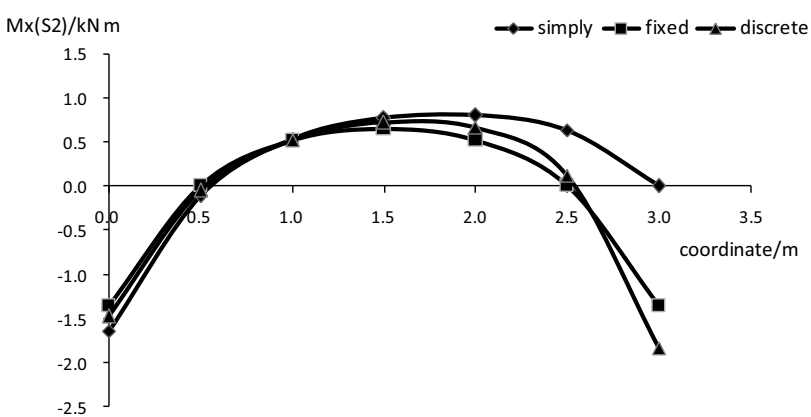

Figure 6. Mx diagram of node 3,10,17,24,31,38,45.

From figure 3 and figure 4, we can see that the difference of displacement is large when applying to different constraint conditions.We can learn that the difference near the midspan is largest and the difference at the lower right is greater than that at the upper left; From figure 5 and figure 6, you can see that the moment varies widely in the lower right, whears the difference in the cross is small. The result shows that the constraints have a significant impact on support moment, whears have little impact on mid-span moment.

\section{CONCLUSION}

1.The method proposed by the author is a good way to solve the problem such as displacement of complex constraint slabs and internal force calculation in the actual engineering.
2.When taking no account of problem of complex constraints, we will find the result of displacement and moment is different.And the result is neither unsafe or old-fashioned.As for this complex constraint slab in the actual project, the author recommend the proposed method in this paper.

\section{ACKNOWLEDGEMENT}

Project supported by Shenyang Jianzhu University (Grant NO.2014083)

Han Yu Project supported by Shenyang Jianzhu University(XKHY-19)

\section{REFERENCES}

1. American Concrete Institute \& ACI Committee 318. 2008. Building Code Requirements for Structural Concrete and Commentary. Farmington Hills, MI: American Concrete Institute.

2. Eyre, J.R.2008.Surround stiffness to membrane action in concrete slabs.Magazine of Concrete Research 59(2):107119.

3. Johnson, D. 2010. On the safety of the strip method for reinforced concrete slab design.Computers and Structures 79(11):2425-2430

4. Muthu ,K .U. \& Amarnath, K.. 2007. Load deflection behavior of partially restrained slab strips.Engineering Structures 29(5):663-674.

5. Taylor, S. E. \& Mullin, B. 2009. Arching action in FRP reinforced concrete slabs. Construction and Building Materials20(2):71-81.

6. Wang Qingxiang \& Wang Gang. 2010. Experiment Study on Compressive Membrane Action of Slab Strips Restrained by Shear Walls.Key Engineering Materials41(7):739-743.

7. Zheng, Y. \& Robinson ,D. 2008. Analysis of compressive membrane action in concrete slabs. Proceedings of the Institute of Civil Engineer161(1):21-31. 